\title{
ORTHOPTERAN DIVERSITY AT KERANIGANJ, DHAKA
}

\author{
Mahmuda Aktar, Md. Aminul Islam¹ and Md. Abdul Alim* \\ Department of Zoology, Jagannath University, Dhaka-1100, Bangladesh
}

\begin{abstract}
This study was conducted to assess the divesity of Orthopteran species at some grasslands and crop fields of Keranigonj upazila in Dhaka district, Bangladesh from April, 2014 to September, 2014. A total of 20 species under 18 genera belonging to 7 families have been recorded. Among them 4 species were more common, 6 species were moderately distributed and 10 species documented as rare. The highest number of Orthopterans was from the family Acrididae 60.58\% (10 spp.) followed by Tetrigidae $15.32 \%$ (2 spp.), Gryllidae $14.23 \%$ (4 spp.), Tettigonidae $10.33 \%$ ( $1 \mathrm{sp}$.), Locustidae $2.55 \%$ (1 sp.), Mantidae $2.55 \%$ ( $1 \mathrm{sp}$.), and the lowest from the family Gryllotalpidae $2.19 \%$ (1 sp.). During observation period the number of Orthopterans was highest recorded in the month of May (20.44\%) followed by April (19.34\%), June (17.52\%), July (14.60\%), August (14.23\%), and the lowest in September (13.87\%). Shannon's diversity index and Simpson's diversity index represent moderate value $(H=2.82)$ and moderately low value $(\lambda=0.07)$, respectively indicating moderate diversity richness for Orthopteran species. The value of species evenness $(\mathrm{E}=0.94)$ tends to be higher indicating that the species are eventually distributed.
\end{abstract}

Key words: Orthopteara, diversity, abundance, Acrididae, Shannon's index, Simpson's index, evenness

\section{INTRODUCTION}

The insect order Orthoptera includes grasshoppers, locust, katydids, crickets, etc., having a general cylindrical body of moderate to large size, with elongated hind legs and musculature adapted for jumping. Over 17,250 orthopteran species are identified throughout the world (Thakkar et al. 2015). Orthoptera has become one of the most important invertebrate group for environmental monitoring and assessment (Jamison et al. 2002). Orthopteran insects are essential elements in trophic food webs as they represent first order consumers and often comprise a considerable fraction of the arthropod biomass in grassland ecosystems (Odum et al. 1962). The most important variables determining Orthoptera occurrence are vegetation structure and climate (Hochkirch et al. 2008, Weyer et al. 2012). Belovsky (2000) reported that some grasshoppers are ecological indicators of ecosystem. Luoto et al. (2000) noted that many species of Orthoptera can be highly destructive to crops. Orthopterans are especially interesting to study in relation to semi natural grasslands due to some significant causes, as their sensitivity to environmental

*Author for correspondence: <maalimzooljnu@gmail.com>. ${ }^{1}$ Department of Zoology, University of Dhaka, Dhaka-1000, Bangladesh.

(c) 2018 Zoological Society of Bangladesh DOI: http://dx.doi.org/10.3329/bjz.v46i1.37623 
changes, year-round presence and critical role in grassland habitats (Gardenfors et al. 2000). For that reason, these insects are perfect organisms to observe the effects of climate and agricultural land use on biodiversity.

Diversity indices are statistics used to summarize the diversity of a population in which each member belongs to a unique group. Generally Shanon diversity index $(\mathrm{H})$ and Simpson diversity index $(\lambda)$ are commonly used to evaluate the diversity richness of organisms present in an area. Typical values of $\mathrm{H}$ are generally between 1.5 and 3.5 in most ecological studies, and the index is rarely greater than 4 (Shannon and Weiner 1949). The Shannon index increases as both the richness and the evenness of the community increase. Simpsons's diversity index $(\lambda)$ was calculated since it is well accepted that all species at a site. The value of $\lambda$ ranges between 0 and 1 (Simpson 1949). As species richness and evenness increase, so diversity increases.

Keraniganj is a semi-rural area, stands on the southwest side of Dhaka city. River Buriganga and Dhaleswari are on the east and the west borders, respectively. The study area mainly comprises of plain agricultural land and almost flat with a few undulations. However, no detailed work on the diversity of Orthopterans in the grassland and crop field of Keraniganj Upazila of Dhaka district has been done to date. Keeping in view with this fact here an attempt has been made to collect, identify and calculate diversity, species richness and evenness of the Orthopteran fauna of Keranigonj.

\section{MATERIAL AND METHODS}

Study site: The study was conducted in different grasslands and crop fields at Keraniganj in Dhaka district. Geographically the area Keraniganj Upazila is $166.87 \mathrm{sq} \mathrm{km}$, located in between $23^{\circ} 37^{\circ}$ and $23^{\circ} 47^{\circ}$ North latitudes and in between $90^{\circ} 13^{\prime}$ and $90^{\circ} 29^{\circ}$ East longitudes (Fig. 1).

Materials: Sweep net, collecting jar and polythene bag, cotton, ethyl acetate, a pair of forceps and needle, camera (Canon), magnifying glass, envelopes, permanent ink pen and label paper were used.

Samplings and identification: Sampling of the Orthopterans was carried out one day per week from April, 2014 to September, 2014. Sampling was executed from 7.00 a.m. to 2.00 p.m. where Orthopterans were directly collected by hand and sweep net. After collection, insects were kept into a plastic jar that contained cotton soaked in ethyl acetate. The Orthopterans were stretched and pinned then oven dried at $60^{\circ} \mathrm{C}$ for $48 \mathrm{hrs}$ in laboratory. Afterwards preservation, the samples were set in wooden boxes (Thakkar et al. 2015). Identification of Orthopterans was performed using the keys developed and followed by Capinera et al. (2004), Uvarov (1921), Kirk and Bomar (2005). 


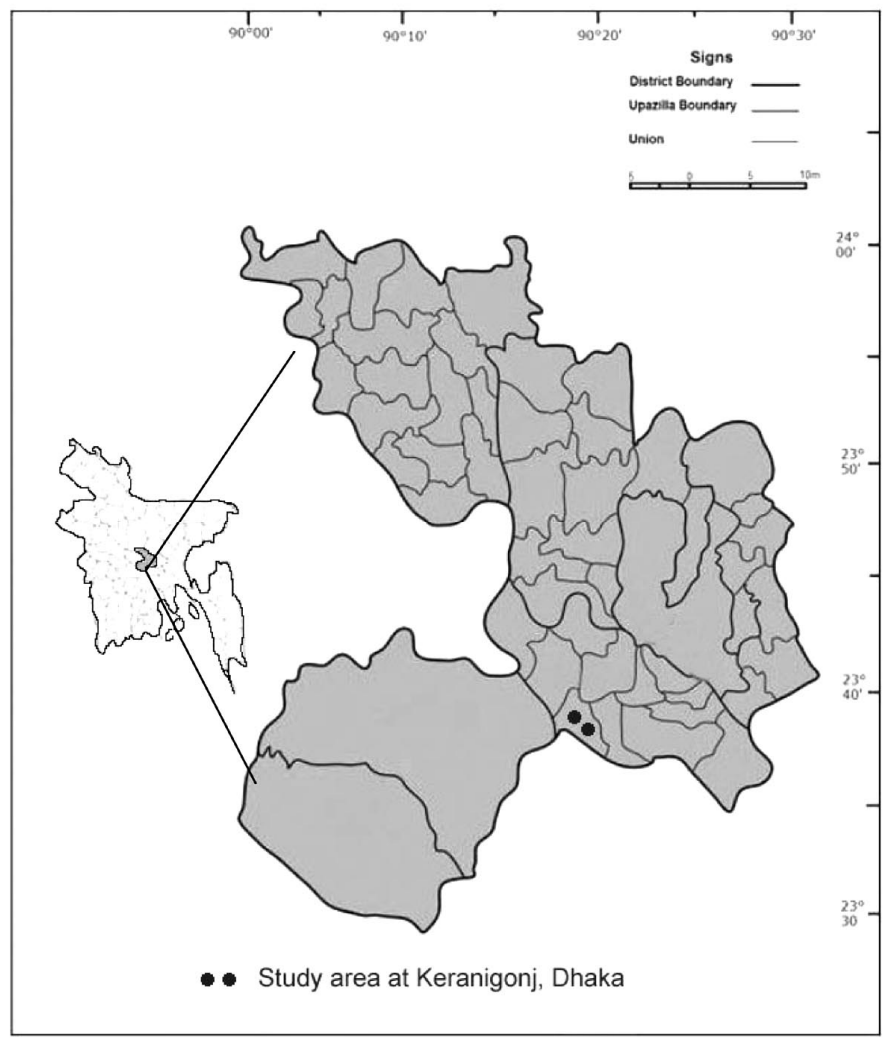

Fig. 1. Map of old Dhaka district in Bangladesh indicating the study area of Keranigonj.

Diversity richness: As a measure of diversity, the most popular and widely used Shannon's diversity index (H) (Shannon and Weiner 1949) and Simpson's diversity index $(\lambda)$ (Simpson 1949) were used as model. The equations for the two indices are:

$$
\begin{aligned}
& \text { Shannon's diversity index }(\mathrm{H})=\sum_{i=1}^{5} p_{i} \ln p_{i} \\
& \text { Simpson's diversity index }(\lambda)=\sum_{i=1}^{5} p_{i}^{2}
\end{aligned}
$$

where, $p$ is the proportion $(\mathrm{n} / \mathrm{N})$ of individuals of one particular species found (n) divided by the total number of individuals found (N), $\ln$ is the natural $\log , \Sigma$ is the sum of the calculations and $S$ is the number of species.

Simpson index of diversity $(1-\lambda)$ : The probability that two randomly selected individuals in a community belong to different categories e.g. species. 
Simpson reciprocal index $(1 / \lambda)$ : The number of equally common categories e.g. species that will produce the observed Simpson's index.

Species evenness $(E)=\frac{H}{\ln (S)} ; S$ is total number of species.

\section{RESULTS AND DISCUSSION}

A total of 274 individuals of 20 species of 18 genera belonging to 7 families of Orthoptera were recorded from different grasslands and crop fields during study period (Table 1). In April, a total of 53 individuals were collected. The highest number (8) was recorded of the species Patanga japonica (Acrididae), and the lowest number (1) for Scapteriscus borellii and Schistocera gregeria of the family Gryllotalpidae and Locustidae, respectively. In this month no individual of Mantis religiosa, Valanga irregularis and Scudderia furcata was found. A total of 56 individuals were collected in May; the highest number (9) was recorded of the species P. japonica (Acrididae) and the lowest number (1) of the species $S$. furcata (Tettigoniidae) as well as Melanoplus punctulatus (Acrididae). No individual of S. borellii, S. gregeria, M. religiosa, V. irregularis was recorded in this month. A total number of 48 individuals were brought from study area in July; the highest number (7) was recorded of the species P. japonica (Acrididae), and the lowest number (1) of the species were $M$. religiosa (Mantidae), V. irregularis (Acrididae), Euparatettix personatus (Tetrigidae), Lepidogryllus comparatus, Acheta domesticus, Megalogryllus clamosus (Gryllidae). In July, a total of 40 individuals were collected. The highest number (8) was observed of the species Tetrix subulata (Tetrigidae), and the lowest number (1) of the species S. gregaria (Locustidae), M. reliogiosa (Mantidae), Acrida. exaltata, S. marmorata (Acrididae) and L. comparatus (Gryllidae). In this month no individual of the species of Euparatettix personatus, V. irregularis, M. punctulatus, A. domesticus, M. clamosus, S. borellii, was espied. In August, a total of 39 individuals was collected. The highest number (6) of Orthopterans was recorded of the species Dichtromorpha viridis (Acrididae), and the lowest number (1) of the species A. exaltata, V. irregularis, M. punctulatus, M. differentialis, Trimerotropis sparsa (Acrididae) and A. domesticus (Gryllidae), S. borellii (Grylotalpidae). No individual of the species of M. religiosa, V. irregularis, S. furcata was found in this month. In September, a total of 38 individuals were collected. The highest number (5) was observed of the species Metioche vittaticollis (Gryllidae), and the lowest number of the species Stenacris vetripennis, M. punctulatus, M. differentialis, T. sparsa (Acrididae), S. furcata (Tettrigoniidae), M. clamosus (Gryllidae). The species S. gregaria, A. exaltata, M. religiosa, Spharagemon marmorata, S. furcata were not found in this month. 


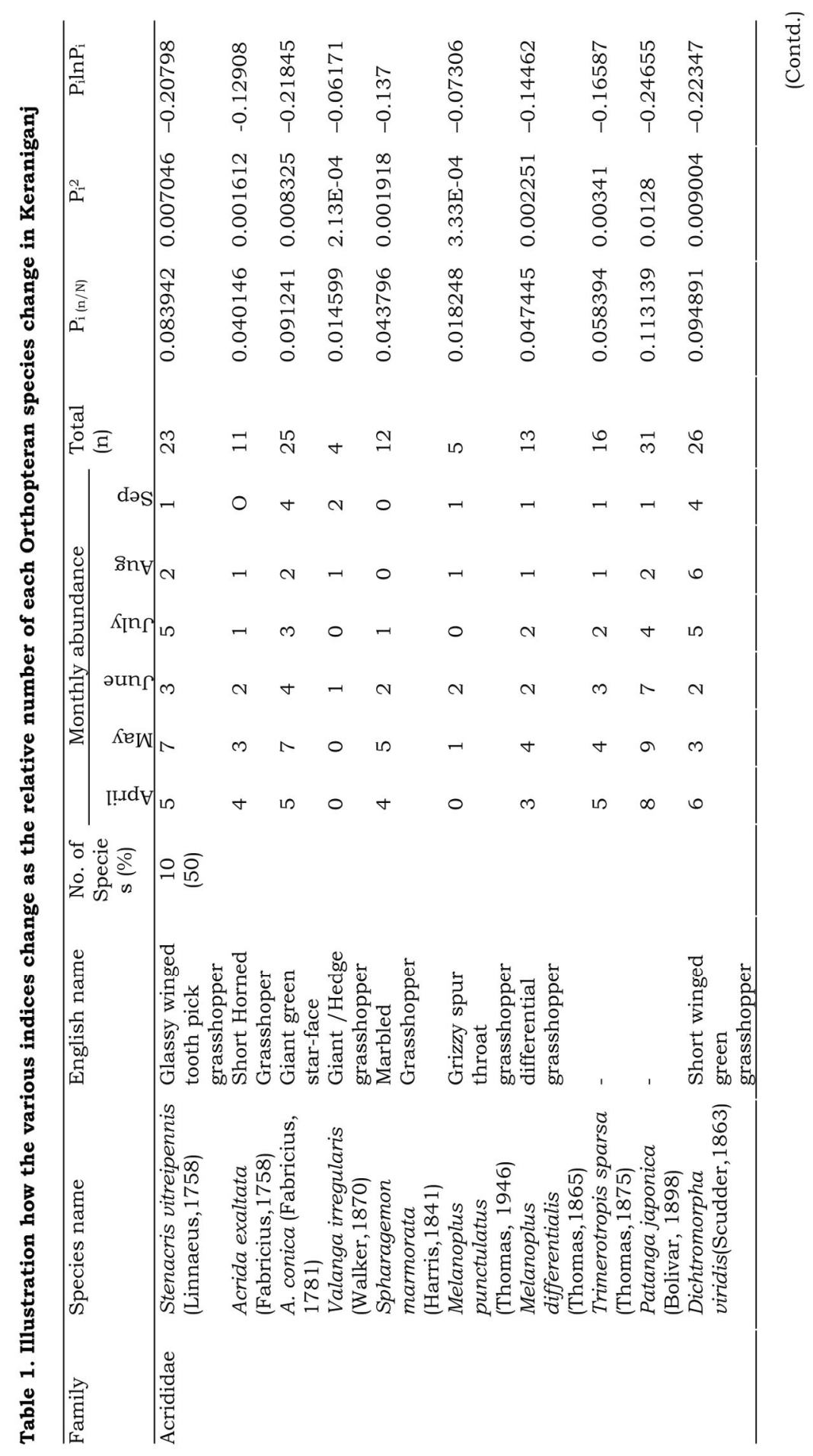




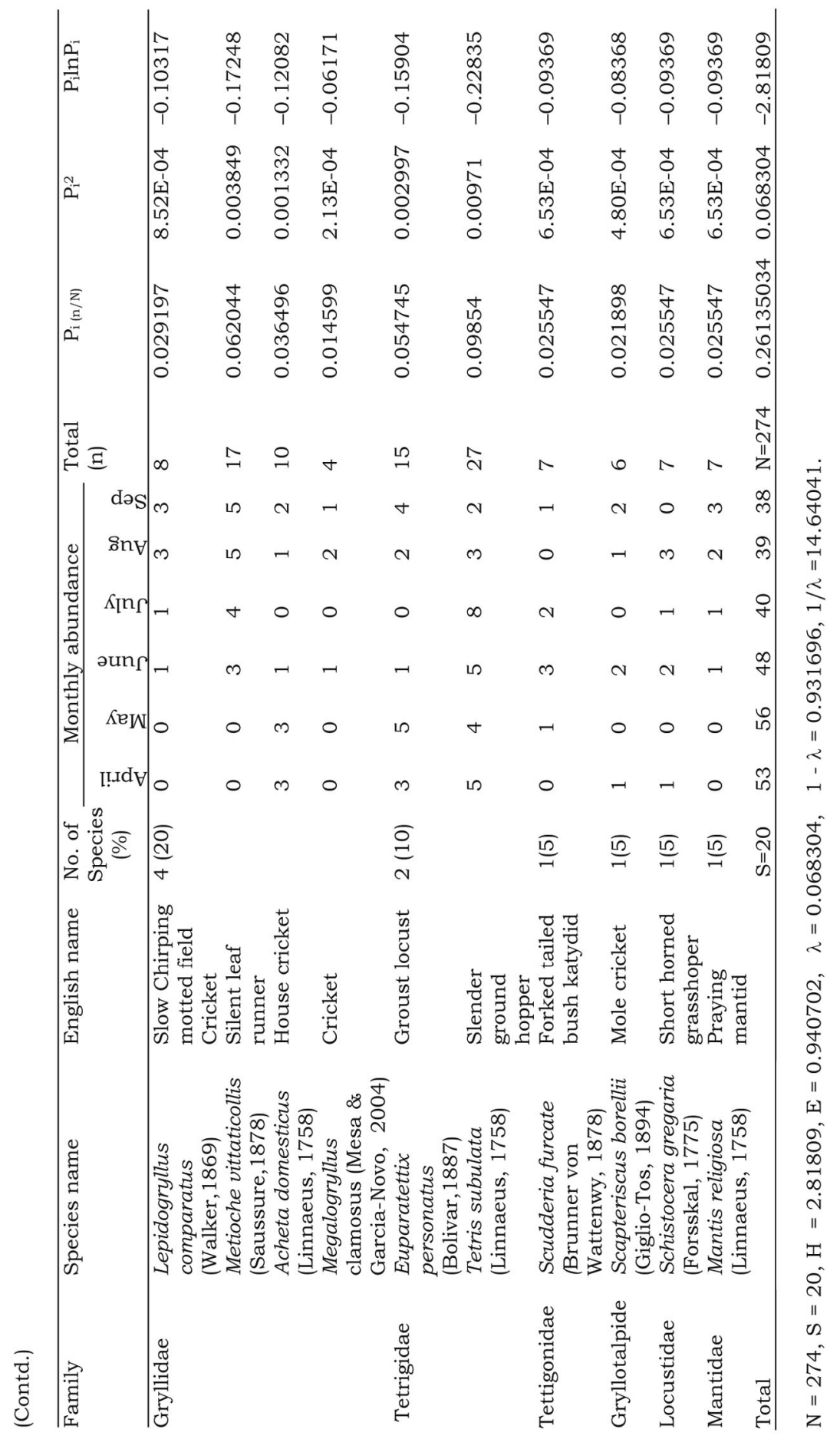


Among them P. japonica (31) was the most dominant species of Orthoptera in terms of number of individuals followed by $T$. subulata (27), D. viridis (26), A. corica (25), S. vetripennis (23). Among the observed species 4 were more common and available having more than 23 individuals, 6 species were moderately distributed having more than 10 individuals, 10 species recognized as rare because having less than 10 individuals of each (Table 1). The value of different indices of species diversity is also shown in the Table 1. The Shannon's diversity index $(H)$ and Simpsons's diversity index $(\lambda)$ for Orthopteran insect species at Keraniganj area are 2.82 and 0.07 , respectively. The value of species evenness (E) is 0.94 .

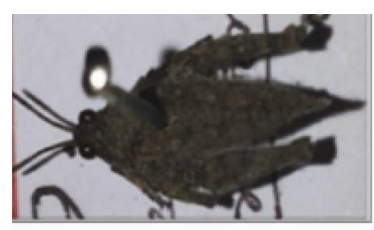

Spharagemon marmorata

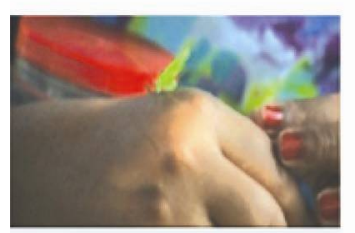

Scudderia furcate

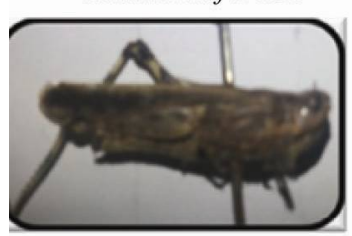

Patanga japonica

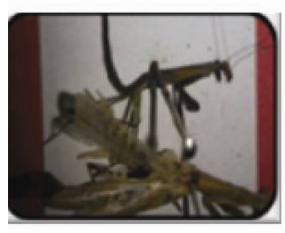

Mantis religiosa

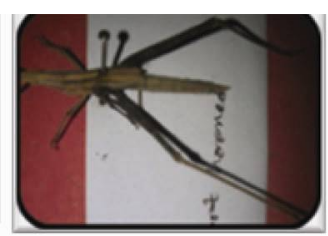

Acrida exaltata

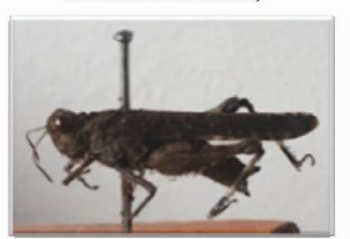

Melanoplus punctulatus
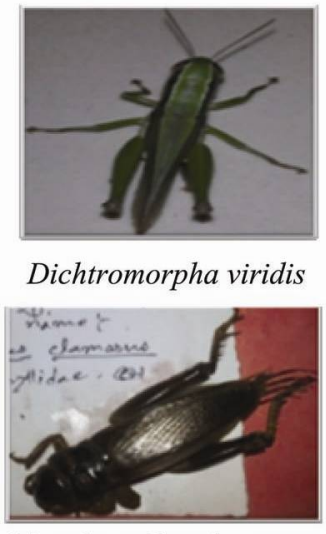

Megalogryllus clamosus

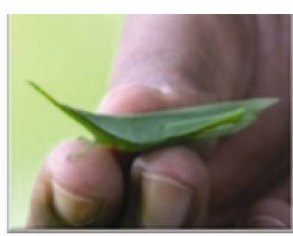

Acrida conica

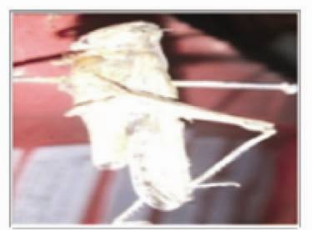

Melanoplus differentialis

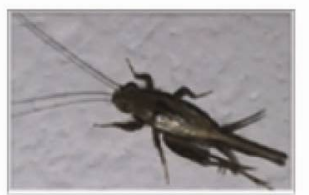

Lepidogryllus comparatus

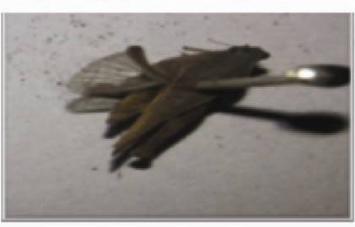

Euparatettix personatus

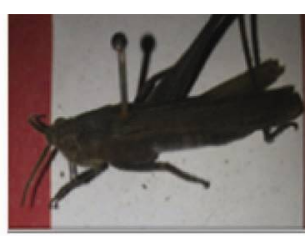

Valanga irregularis

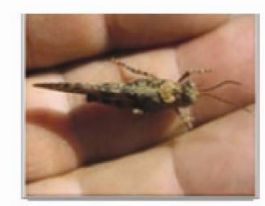

Trimerotropis sparsa

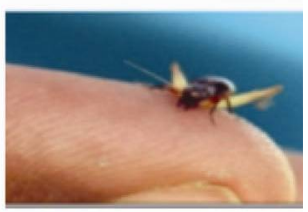

Metioche vittaticollis

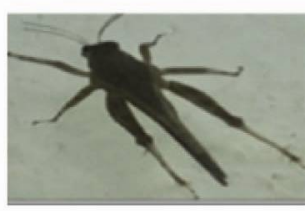

Tetrix subulata

Plate 1. Some Orthopteran species recorded in different places of Keraniganj.

Month-wise population rarefaction (cumulative) curve of the faunal assemblage of Orthopterans at Keraniganj is shown in the Figure 2. The highest number of Orthopterans was in the family Acrididae (60.58\%) followed by Tetrigidae (15.32\%), Gryllidae (14.00\%), Tettigonidae (2.60\%), Locustidae (2.55\%), 
Mantidae (2.55\%), and Gryllotalpidae (2.19\%) (Fig. 3). In the month wise record of Orthopteran insects in this study was shown that the highest Orthopterans specimen was recorded in the month of May (20.44\%) followed by April (19.34\%), June (17.52\%), July (14.60\%), August (14.23\%) and September (13.87\%) (Fig. 4).

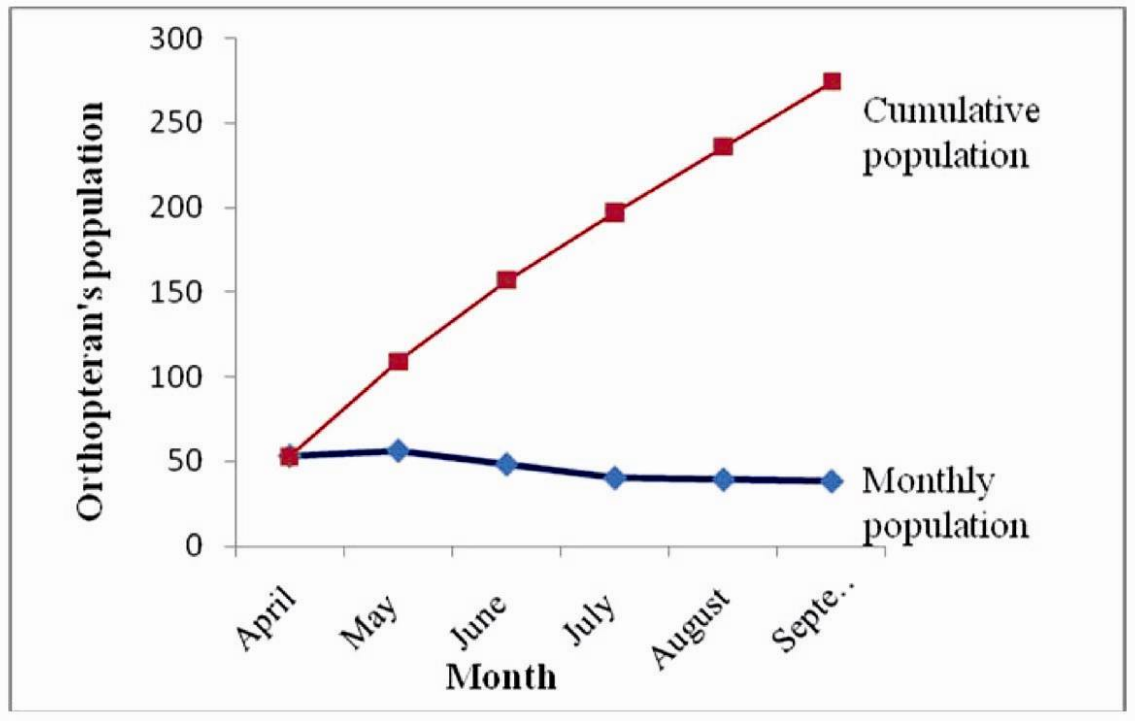

Fig. 2. Month-wise population rarefaction (cumulative) curve of the faunal assemblage of Orthopterans at Keraniganj.

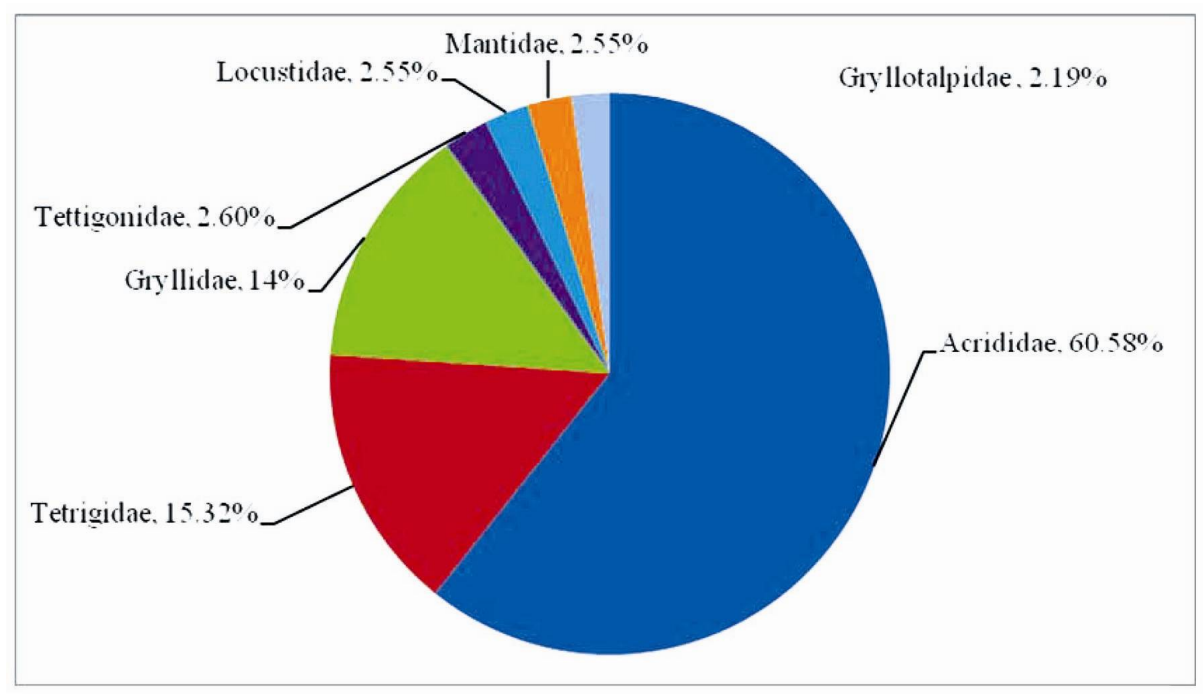

Fig. 3. Family-wise population of different species at Keraniganj. 
The present study illustrated a good diversity of Orthopteran species at Keranigonj. Maximum diversity shown by family Acrididae (10 species - 50\%) followed by Gryllidae ( 4 species - 20\%), Tetrigidae ( 2 species, 10\%), Tettigonidae ( 1 species, 5\%), Mantidae ( 1 species - 5\%), Locustidae ( 1 species - 5\%) and Gryllotalpidae (1 species - 5\%) (Table 1). This result shows more or less similarities with some works in Gujarat of India where 18 species belonging to 5 families were recorded by Pilo et al. (1996) from Shoolpaneshwar Wildlife Sanctuary, Parikh et al. (2001) recorded 4 families and 36 Species from Girpa. This observation is parallel with the investigation of Chitra et al. (2000) who reported 28 species of short horned grasshoppers from rice field of Coimbatore. Thirty three species of locusts and grasshoppers have been reported by Usmani et al. (2010) from Western Uttar Pradesh of India. Jadhao and Khurad (2011) described only one species of grasshoppers i.e., Hieroglyphus banian out of 23 species of insect pest of rice ecosystem from Maharshtra.

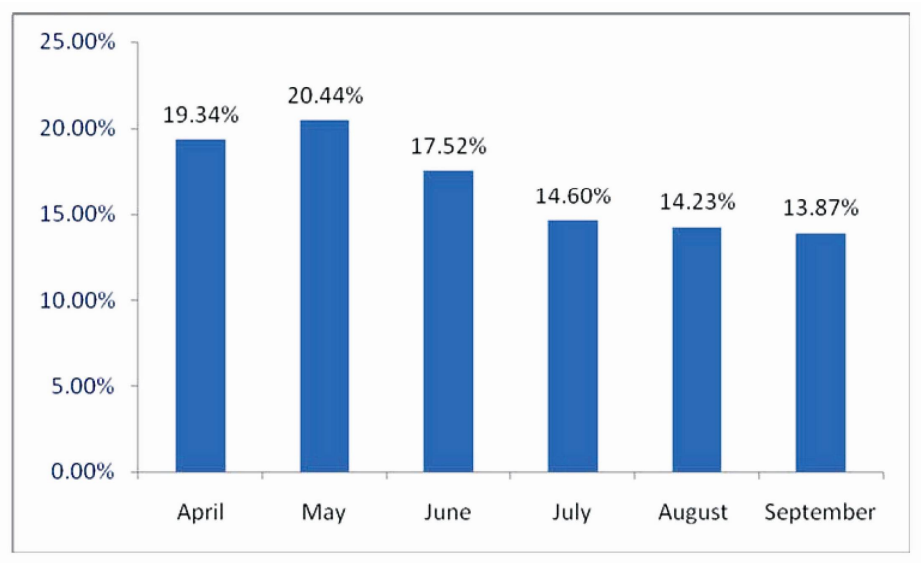

Fig 4. Month-wise (2014) population of different species at Keraniganj.

The Orthopteran population studied at Keraniganj area cannot be proved that formed real ecological communities. Neither direct interactions, nor species coalitions could be established in this research, therefore, these Orthoptera fauna were considered only as species assemblages. The species composition of these assemblages is similar to those that were described by Gausz (1969) from the Middle and Lower Tisza districts of Hungary. The Orthoptera fauna of Keranigonj is not well known. The relation of great species richness of the city sides is probably due to the moderate disturbances and the special, stripe-like shape of these grassland habitats, which promotes the migration and recolonization of populations, and therefore compensates the stronger disturbances and extinction. 
The concept of species diversity generally consists of two components, namely species richness and species evenness. Species richness is computed by using Shannon's diversity index $(H)$ and Simpsons's diversity index $(\lambda)$. Ganeshaih et al. (1997) stated that the diversity indices $H$ and $\lambda$ appearede useful as they incorporated species richness. In this study, Shannon diversity index and Simpsons diversity index represent moderate value $(\mathrm{H}=2.82)$ and moderately low value $(\lambda=0.07)$, respectively indicating moderate diversity richness for Orthopteran species in Keranigonj area (Table 1). Ludwig and Reynolds (1988) revealed that the value of $\lambda$ decrease with increasing diversity. Evenness index provides an insight into the relative abundance of the species in the community. Sanjayan et al. (1995) described the value of $\mathrm{E}$ tend to be zero indicates that the species becomes more dominant in a community. The value of $\mathrm{E}$ tends to be higher indicating the species are evenly distributed. In this study, the value of $\mathrm{E}(.094)$ tends to be higher indicating that the species are eventually distributed.

\section{CONCLUSION}

The present study is a work of six months which deals with the taxonomy, distribution and abundance of Orthoptera. This is the first report from Keranigonj as no notable work has been done on this aspect. Most approach for estimating species richness is based on extrapolation from known species accumulation curve, describes species richness in a local homogeneous assemblages as a function of sampling effort. In the present study the species accumulation curve could not attain asymptote after six sampling in six months indicated that most of the probable species have not been encountered during the inventorying process. Better understanding of the abundance, species richness and seasonal composition of Orthopteran communities has been achieved in this investigation, which should be very useful for improving predictive models and developing management guidelines for their control.

A long term study is needed to observe the species occurrence in all seasons and their interaction with the environmental changes in order to get better and comprehensive information. However, this study will definitely add more information to the existing knowledge of entomology in Bangladesh.

\section{LITERATURE CITED}

BELOVSKY, E.G., JOERN, A. and LOCKWOOD, J. 2000. Plus and Minus: The Grasshopper Problem on a Regional Basis and a look at Beneficial Effects of Grasshoppers. Grasshopper 16: 1-5.

CAPINERA, J.L., SCOTT, R.D. and WALKER, T.J. 2004. Field Guide to Grasshoppers, Katydids, and Crickets of the United States. Cornell University Press, 289 pp. 
CHITRA, N., SOUNDARARAJAN, R.P. and GUNATHILAGARAJ, K. 2000. Orthoptera in rice fields of Coimbatore. Zoos' Print Journal 15(8): 308-311.

GANESHAIH, K.N., CHANDRASEKARA, K. and KUMAR, A.R.V. 1997. A new measure of biodiversity based on biological heterogeneity of communities. Current Science 73(2): 128-133.

GARDENFORS, U. 2000. The red-list of Swedish species. Art Databanken, Swedish Agricultural University, Uppsala.

GAUSZ, J. 1969. Faunistical and ecological investigations of Orthoptera in the region of the MiddleTisza (Kisköre). Tiscia 5: 55-68.

HOCHKIRCH A., GARTNER, A.C. and BRANDT, T. 2008. Effects of forest-dune ecotone management on the endangered heath grasshopper, Chorthippus vagans (Orthoptera: Acrididae). Bull Entomol. Res. 98: 449-456.

JADHAO, M.F. and KHURAD, A.M. 2011. Insect Pests Complex of Rice Ecosystem in Eastern Vidarbha of Maharashtra, India. Res. Anal. \& Eval. 2(24): 19-21.

JAMISON, B.E., ROBEL, R.J., PONTIUS, J.S, and APPLEGATE, R.D. 2002. Invertebrate biomass: associations with lesser prairie-chicken habitat use and sand sagebrush density in southwestern Kansas. Wildl. Soc. Bull. 30:517-526.

KIRK and BOMAR. 2005. Guide to the Grasshoppers of Wisconsin Publisher: Wisconsin Dept. of Natural Resources.

LUDWIG. J. A. and REYNOLDS J. F. 1988. Statistical Ecology-A primer on methods and computing. John Willy and Sons, New York.

LUOTO, M. 2000. Modelling of rare plant species richness by landscape variables in an agriculture area in Finland. Plant Ecol. 149:157-168.

ODUM E.P., CONNELL C.E. and DAVENPORT L.B. 1962. Population energy-flow of 3 primary consumer components of old-field ecosystems. Ecology 43: 88

PARIKH, P. 2001. Studies of lesser known fauna of Gir PA with special reference to Invertebrates. Department of forest, Wildlife Division, Sasan Gir, Gujarat.

PILO, B., PATHAK, B., KUMAR, B., MURUKSAN, V., VINOD, K. and KUMARI, S. 1996. Biological diversity of Gujarat-Current knowledge. Gujarat Ecological Commission, Vadodara.

SANJAYAN, K.P., M.C. MURALIRANGAN, P., SURESH, D., CHAD, S. and ALBERT, S. 1995. The plant community structure of the Namangalam Reserve Forest. Tamil Nadu: a paradigm of the spatial distribution pattern in a natural scrub-jungle ecosystem. Int. J. Eco. \& Environ. Sci. 21 : 297-307.

SHANNON, C.E. and WIENER, W. 1949. The mathematical theory. University of Illinois press, Urbana. 117pp.

SIMPSON, E.H. 1949. Measurement of diversity. Nature 163: 688.

THAKKAR, B., PARMAR, S. and P. PARIKH. 2015. Study on diversity of Orthoptera fauna in South Gujarat, India. Int. J. Pure \& App. Zool. 2(4): 368-374.

USMANI, M., KKHAN, M.I. and KUMAR, H.I.R.D.E.S.H. 2010. Studies on Acridoidea (Orthoptera) of Western Uttar Pradesh. Biosystematica 4(1): 39-58.

UVAROV, B.P. 1921. Notes on the Orthoptera in the British Museum. 1. The group of Euprepocnemini. Trans. Ent. Soc. Lond. 1(2): 106-143.

WEYER, J., WEINBERGER, J. and HOCHKIRCH, A. 2012. Mobility and microhabitat utilization in a flightless wetland grasshopper, Chorthippus montanus (Charpentier, 1825). J. Insect Conser. 16: 379-390.

(Manuscript received on 25 March, 2018; revised on 12 June, 2018) 